\title{
¿DÓNDE SE ENJUICIA EL DESPIDO DE UN TELETRABAJADOR?
}

\author{
Carlos Cordero Márquez \\ Abogado laboralista \\ PriceWaterhouseCoopers (PwC) Tax \& Legal
}

La implantación forzosa del trabajo a distancia, o teletrabajo, como consecuencia de la pandemia mundial del COVID-19 ha motivado que una modalidad de prestación de servicios, residual o cuasi inexistente, se haya convertido -al menos durante un periodo de tiempo- en el medio más extendido de prestación de servicios laborales.

Con el fin de dar respuesta a la problemática dimanante de esta forma de trabajo, se publicó en fecha 23 de septiembre de 2020 el Real Decreto-ley 28/2020, de 22 de septiembre, de trabajo a distancia, sustituido posteriormente por la Ley 10/2021, de 9 de julio, de trabajo a distancia, la cual regula cómo debe organizarse la prestación de servicios cuando el lugar de prestación de los mismos no es el centro de trabajo, sino el domicilio de la persona trabajadora u otro elegido por esta.

Así, a lo largo de la precitada Ley 10/2021, de 9 de julio, se define y desarrolla el trabajo a distancia y se regula el contenido del acuerdo laboral que debe existir entre las partes para su adecuación a Derecho. Junto con esta regulación, el legislador introduce un nuevo artículo en la Ley 36/2011, de 10 de octubre, reguladora de la Jurisdicción Social (en adelante: LRJS): el 138 bis, intitulado "Tramitación en reclamaciones sobre acceso, reversión y modificación del trabajo a distancia", donde se regula un procedimiento específico para resolver los conflictos dimanantes de dicha modalidad de prestación de servicios.

No obstante lo anterior $-\mathrm{y}$ a pesar del detalle con el que la norma regula de forma sustantiva cómo debe ser la prestación de servicios, cuáles las obligaciones para las partes y cuándo la prestación entra dentro del ámbito de aplicación de la norma-, el legislador, bien por olvido, bien conscientemente, deja sin regular un extremo notoriamente importante para la resolución de conflictos: la competencia territorial judicial en caso de controversias entre las partes.

De entrada, la competencia judicial por razón del territorio aparece regulada en el art. 10 de la LRJS, que dice así:

Copyright: () Editorial Universidad de Sevilla. Este es un artículo de acceso abierto distribuido bajo los términos de la licencia de uso y distribución Creative Commons Reconocimiento-NoComercialSinObraDerivada 4.0 (CC BY-NC-ND 4.0)

e-ISSN: 2660-4884

Trabajo, Persona, Derecho, Mercado 4 (2021) 233-236 https://dx.doi.org/10.12795/TPDM.2021.i4.12 
"Artículo 10. Competencia territorial de los Juzgados de lo Social.

La competencia de los Juzgados de lo Social se determinará de acuerdo con las siguientes reglas:

1. Con carácter general será juzgado competente el del lugar de prestación de los servicios o el del domicilio del demandado, a elección del demandante (...)”.

Aplicando la regla general al trabajo a distancia o teletrabajo, se concluiría que, dado que el legislador no ha modificado la LRJS en este extremo, y atendiendo a que la Ley 10/2021 recoge expresamente que el trabajo a distancia se realizará en el "domicilio de la persona trabajadora o en el lugar elegido por esta", los conflictos nacidos entre empresarios y trabajadores a distancia deberían resolverse en el foro correspondiente al domicilio de la empresa o en el del domicilio del trabajador, por ser el lugar de prestación de los servicios. Así lo ha entendido el Juzgado de lo Social número 4 de Córdoba, Sentencia 281/2021, de 5 de octubre, que concluía lo siguiente:

"En este sentido y aplicando lo dispuesto en artículo 10.1 de la Ley Reguladora de la Jurisdicción Social, será Juzgado competente el lugar de prestación de los servicios o el del domicilio del demandado a elección del demandante. Si los servicios se prestaran en lugares de distintas circunscripciones territoriales, el trabajador podrá elegir entre aquel de ellos en que tenga su domicilio, el del contrato, si hallándose en él el demandado pudiera ser citado, o el del domicilio del demandado.

En el presente caso el trabajador eligió su domicilio, sito en Córdoba y donde venía teletrabajando debido a la situación sanitaria que estábamos sufriendo, por lo que se consideran competentes para conocer el presente asunto los Juzgados de lo Social de Córdoba y en concreto este órgano jurisdiccional por las normas de reparto".

Sin embargo, existen varias razones que podrían conducir a alcanzar una conclusión contraria y considerar que, en el trabajo a distancia o teletrabajo, el lugar de prestación de los servicios - como ubicación física predeterminante del foro judicialno se correspondería con el domicilio de la persona trabajadora, sino con el del centro de trabajo de referencia, que debe ser fijado en el acuerdo de trabajo a distancia de forma obligatoria.

En primer lugar, el Preámbulo del Real Decreto-ley 28/2020 ya venía indicando que "la vinculación necesaria a un centro de trabajo, etc., son condiciones esenciales que deben figurar de manera expresa sin perjuicio de la legislación estatutaria y de los convenios colectivos aplicables”. Idéntico contenido incorpora la Ley 10/2021. Por su parte, el art. 7 de esta Ley establece que:

"Será contenido mínimo obligatorio del acuerdo de trabajo a distancia, sin perjuicio de la regulación recogida al respecto en los convenios o acuerdos colectivos, el siguiente: (...) e) Centro de trabajo de la empresa al que queda adscrita la persona trabajadora a distancia y donde, en su caso, desarrollará la parte de la jornada de trabajo presencial". 
A lo anterior, debemos añadir que su DA $3^{\text {a }}$-intitulada "Domicilio a efectos de considerar la Autoridad Laboral competente y los servicios y programas públicos de fomento de empleo aplicables- dice:

"En el trabajo a distancia, se considerará como domicilio de referencia a efectos de considerar la Autoridad Laboral competente y los servicios y programas públicos de fomento del empleo aplicables, aquel que figure como tal en el contrato de trabajo y, en su defecto, el domicilio de la empresa o del centro o lugar físico de trabajo".

A mayor abundamiento, el art. 4, con el título "Igualdad de trato y de oportunidades y no discriminación”, también refuerza -en su primer apartado- el argumento de que el centro de trabajo de adscripción constituye el lugar de prestación de los servicios y, por tanto, el lugar de referencia para el ejercicio de los derechos y obligaciones, al señalar que:

\begin{abstract}
"Las personas que desarrollan trabajo a distancia tendrán los mismos derechos que hubieran ostentado si prestasen servicios en el centro de trabajo de la empresa, salvo aquellos que sean inherentes a la realización de la prestación laboral en el mismo de manera presencial, y no podrán sufrir perjuicio en ninguna de sus condiciones laborales, incluyendo retribución, estabilidad en el empleo, tiempo de trabajo, formación y promoción profesional”.
\end{abstract}

Por su parte, otras razones, de índole más práctico, permiten oponerse a la consideración del domicilio de la persona trabajadora como lugar de prestación de servicios a efectos del foro judicial, como ocurriría con la posibilidad de amparar conductas como el forum shopping o foro de conveniencia, de forma que las personas trabajadoras podrían elegir el foro judicial que más beneficiase a sus intereses, máxime cuando el procedimiento del 138 bis LRJS es firme en la instancia con carácter general.

De este modo, la norma parece señalar que el lugar de permanencia física no se corresponde con el lugar de prestación de los servicios; que, en todo caso, sigue siendo el centro de trabajo de adscripción, pues es donde el trabajador mantiene todos los derechos colectivos, electivos y de formación. Entender que el centro de trabajo de adscripción es el que fija el foro para algunas materias (electivas, formativas, etc.) y que su domicilio lo fija para otras, constituye una suerte de espigueo normativo que alteraría la competencia territorial judicial. Llevando el argumento a sus últimas consecuencias, cabe plantearse qué ocurriría si el trabajador decidiera establecer su domicilio en Portugal, en Andorra o en cualquier otro país de la Unión Europa, así como el impacto que ello tendría en la resolución de los conflictos nacidos de la relación laboral.

De este modo, el hecho de considerar el "lugar de prestación de los servicios" como el "domicilio del demandante", conllevaría que el empresario se vería forzado a litigar en lugares donde no tuviera centro de trabajo ni tampoco hubiera generado 
negocio; precisamente por eso se explica la mención al "lugar de prestación de los servicios" que hace la norma. Y lo anterior queda reforzado si se tiene en cuenta que, en Derecho laboral, no es factible la sumisión expresa para resolver los conflictos en materia laboral, como ya dijera la STS de 16 de febrero de 2004 cuando señaló que:

"La sumisión expresa no puede ser aceptada en el ámbito de las relaciones laborales, pues la misma no se ajusta ni compagina, en absoluto, con la estructura, naturaleza y fines del contrato de trabajo. El Derecho del Trabajo tiene, como es sabido, una finalidad protectora y tuitiva de la parte más débil de la relación laboral, que es el trabajador, y esa finalidad protectora se vería gravemente quebrantada si se admitiese en el ámbito de la misma la sumisión expresa. Téngase en cuenta que bien en el momento en que se concierta el contrato de trabajo, por razón de la necesidad del trabajador de conseguir un empleo, bien ya vigente tal contrato dada la situación de preeminencia y superioridad que en la relación de trabajo tiene el empresario, puede éste forzar al empleado a que acepte una cláusula contractual por la que se disponga que los conflictos que entre ellos puedan surgir sean resueltos por los Jueces o Tribunales de una determinada circunscripción territorial, a pesar de que el acceso a esos concretos Tribunales o Jueces sea especialmente dificultoso para dicho trabajador. De esta forma se hace más difícil para éste el ejercicio de su derecho fundamental a la tutela judicial efectiva, que proclama el art. 24 de la Constitución, en lo que atañe a los posibles conflictos que puedan surgir en la aplicación y ejecución de su contrato de trabajo. Es claro, pues, que en las relaciones laborales no es posible admitir la validez de los pactos de sumisión expresa”.

Llegados a este punto, habría que preguntarse si es posible que, dado el carácter voluntario del trabajo a distancia para las partes, el empresario limitase los lugares donde el trabajador pudiere prestar servicios. Dicho con otras palabras, si el domicilio del trabajador podría estar limitado geográficamente con el fin de evitar precisamente que el litigio pudiera exceder los lugares donde se prestan servicios. Por otro lado, también cabría cuestionarse sobre si el trabajador tendría la obligación de informar al empresario de un cambio de domicilio o, por el contrario, habría que entender dicha información como perteneciente al ámbito estrictamente personal del trabajador, siendo que, en estos casos, la fijación de un domicilio en uno u otro lugar afectaría a la gestión de la relación laboral propiamente dicha.

En síntesis, debe concluirse que la competencia judicial no puede verse alterada por el lugar donde el trabajador tenga su domicilio; sino que, en materia de trabajo a distancia o teletrabajo, el lugar de prestación de los servicios debe vincularse con el del centro de trabajo de adscripción o referencia, so pena de vulnerar el Orden Público procesal y producir un desequilibrio entre las partes en el proceso, si bien tendrá que ser la Jurisprudencia la que aclare dicha cuestión, dado que la doctrina judicial está aún en sus primeros pasos. 